08

\title{
Структура платиноуглеродных электродов, содержащих различные формы протонпроводящего полимера Nafion
}

\author{
(ㄱ Н.В. Глебова, А.О. Краснова, А.А. Томасов, Н.К. Зеленина, Е.В. Гущина, \\ М.С. Дунаевский, А.А. Нечитайлов
}

Физико-технический институт им. А.Ф. Иофрфе РАН, 194021, Санкт-Петербург, Россия

e-mail: aan.shuv@mail.ioffe.ru

(Поступило в Редакцию 9 фревраля 2017 г.)

Методами сканирующей электронной микроскопии, атомно-силовой микроскопии и циклической вольтамперометрии проведено комплексное сравнительное исследование структуры электродов водородного топливного элемента, состоящих из наноструктурированной платины на углеродной саже, и электродов, содержащих протонпроводящий полимер Nafion, вводимый в электрод в виде раствора и в предварительно коагулированном состоянии. Показано, что в последнем случае значительно (до двух раз) возрастает удельная площадь электрохимически активной платины.

DOI: 10.21883/JTF.2017.11.45132.2201

Как хорошо известно, эффективность топливных элементов во многом определяется свойствами его электродов, в особенности связанными с процессом восстановления кислорода. Во многом структура таких электродов, играющая решающую роль в ионном транспорте гидратированных протонов, массовом транспорте газов и воды и условиях теплообмена, определяет их эффективность. Структура протонпроводящего полимеpa Nafion в таких электродах оказывает существенное влияние на доступность поверхности платины для реакционных газов [1-3]. Обычно Nafion в электрод вводят в виде раствора в органических растворителях с диэлектрической проницаемостью $\varepsilon>10$ (обычно ипропанол) или в коллоидной форме в растворителях c $10>\varepsilon>3$ (например, бутилацетат) [4, 5]. Показано, что электроды с Nafion, введенном в коллоидной форме, в противоположность электродам с Nafion в пленочной форме имеют бо́льшую эффективность. Это предположительно связано со структурным эффектом, заключающимся в том, что относительно крупные частицы коллоидного Nafion меньше блокируют поверхность платины и способствуют созданию более пористой структуры, что способствует интенсификации массового транспорта.

Авторами настоящей работы предложен новый подход, заключающийся в добавлении в электродный материал предварительно коагулированного Nafion. Такой прием приводит к введению в электродный материал полимера Nafion с еще более крупными частицами, что существенно уменьшает его влияние на поверхность платины.

Цель настоящей работы состояла в сравнительном исследовании структуры и свойств электродов, полученных по традиционной технологии, при введении в электрод раствора Nafion (пленочная архитектура) и при введении предварительно коагулированного Nafion.
Для исследования были изготовлены образцы электродного материала и мембранно-электродных блоков (МЭБ) двух типов: содержащие Nafion, введенный в виде водно-изопропанольного раствора и после предварительного коагулирования путем разбавления водноизопропанольного раствора водой.

В качестве платинированной углеродной сажи $(\mathrm{Pt} / \mathrm{C})$ и иономера использовали коммерческий продукт фирмы „Е-ТЕК“ с содержанием платины 40\% и водноспиртовой раствор Nafion фирмы „Ion Power Inc.“ соответственно. МЭБ изготавливали на протонпроводящей мембране типа МФ4-СК производства ОАО „Пластполимер“.

Электродные материалы готовили по двуступенчатой технологии:

- на первом этапе готовили дисперсию платинированной углеродной сажи и Nafion в смеси и-пропанол-вода при отношении твердой фазы к жидкой - т:ж $=1: 40$ путем обработки ультразвуком в У3-ванне типа Bransonic 3510 в течение $=\operatorname{sim} 30 \mathrm{~h}$ до получения визуально однородной дисперсии (так называемые каталитические чернила);

- на втором этапе часть дисперсии высушивали на воздухе.

Nafion вводили в каталитические чернила либо в виде раствора в смеси и-пропанола с водой, взятых в объемах $1: 1$, либо после коагулирования путем добавления воды к водно-изопропанольному раствору Nafion.

МЭБ изготавливали методом намазывания электродного материала на протонпроводящую мембрану через стальную маску с окном $1 \times 1 \mathrm{~cm}^{2}$. Мембрану при этом термостатировали при температуре $85^{\circ} \mathrm{C}[4,6]$. Количество нанесенного материала контролировали гравиметрически.

Микроструктуру образцов изучали методом сканирующей электронной микроскопии. Съемку изображений вели в режиме регистрации прошедших электронов (режим светлого поля) при ускоряющем напряжении $20 \mathrm{kV}$. 
Таблица 1. Параметры сканирования поверхности электродов методом АСM

\begin{tabular}{l|c}
\hline Эффективный радиус зонда & $80-100 \mathrm{~nm}$ \\
\hline Сила давления зонда на образец & $1 \mathrm{nN}$ \\
\hline Радиус области контакта & $3-5 \mathrm{~nm}$ \\
\hline S контакта зонда с поверхностью & $30 \mathrm{~nm}^{2}$ \\
\hline Поле сканирования & $256 \times 256$ picsel \\
\hline $\begin{array}{l}\text { Шаг сканирования для поля } 5 \mathrm{mkm} \\
\text { (5000/256) }\end{array}$ & $20 \mathrm{~nm}$ \\
\hline Глубина сканирования & $1 \mu \mathrm{m}$ \\
\hline Напряжение & $0.05-0.2 \mathrm{~V}$
\end{tabular}

Микроскопические исследования морфологии образцов проводили в естественных условиях, чтобы исключить поверхностные эффекты от напыления проводящего слоя [7].

Для исследования структуры электродов наряду с широко используемым методом сканирующей электронной микроскопии использовалась атомно-силовая микроскопия (ACM). В работе [8] метод микроскопии сопротивления растекания (МСР) был применен для исследования структуры и проводимости протонпроводящей мембраны типа Nafion, сформированной методом полива на электрод. Продемонстрирована прямая связь обволакивания частиц каталитического слоя полимером с ухудшением локальной ионной проводимости мембран. Особенность применения метода МСР в работе [8] заключается в том, что регистрация токовых карт локальной проводимости мембран проводилась в полуконтактном режиме работы микроскопа, т. е. был использован метод полуконтактной микроскопии сопротивления растекания (ПМСР). Этот подход позволил наряду с рельефом идентифицировать области с различным уровнем и типом проводимости, не разрушая и не модифицируя поверхность мембраны. В настоящей работе метод ПМСР был применен к образцу МЭБ в отсутствие электрохимической реакции. При этом сканирование рельефа позволило различать проводящие (платина, углеродная сажа) и непроводящие (Nafion) области.

АСМ измерения в режиме ПМСР проводились на приборе „Solver P47-PRO“ [9] производства компании „NT-MDT“ (Зеленоград, Москва). Использовались проводящие зонды DCP01 [10], время сканирования $15 \mathrm{~min}$. Величина прикладываемого к зонду напряжения находилась в диапазоне от 0.2 до $2 \mathrm{~V}$. Величина прикладываемого напряжения подбиралась таким образом, чтобы значение протекающего между зондом и электродом тока находилось в диапазоне $1-10 \mathrm{nA}$, которому соответствует наибольшая чувствительность токового усилителя АСМ. В табл. 1 приведены условия сканирования.
Удельную площадь поверхности платины $\left(S_{\mathrm{Ptsp}}\right)$ измеряли методом циклической вольтамперометрии в среде $\mathrm{H}_{2} / \mathrm{N}_{2}$ по десорбции водорода, как описано в [11]. Предварительно МЭБ активировали путем циклического изменения потенциала в диапазоне $0-1000 \mathrm{mV}$ до стабилизации ВАХ по методике, представленной в [12].

\section{Результаты}

В табл. 2 приведены характеристики образцов МЭБ, которые были использованы для микроскопических исследований.

На рис. 1 показаны образы поверхности электрода, полученные методами СЭМ и АСМ.

Из рисунка видно, что полученные изображения похожи. Электрод имеет структурные элементы, по форме близкие к шару с характерным размером $50-200 \mathrm{~nm}$, и поры различной формы и размера. При этом диапазон высот (рис. $1, b$, шкала справа) на исследованной площади $1 \times 1 \mu \mathrm{m}^{2}$ составил около $200 \mathrm{~nm}$, что соответствует максимальному наблюдаемому размеру шарообразной частицы. Получение аналогичных результатов при использовании различных методов дает основание

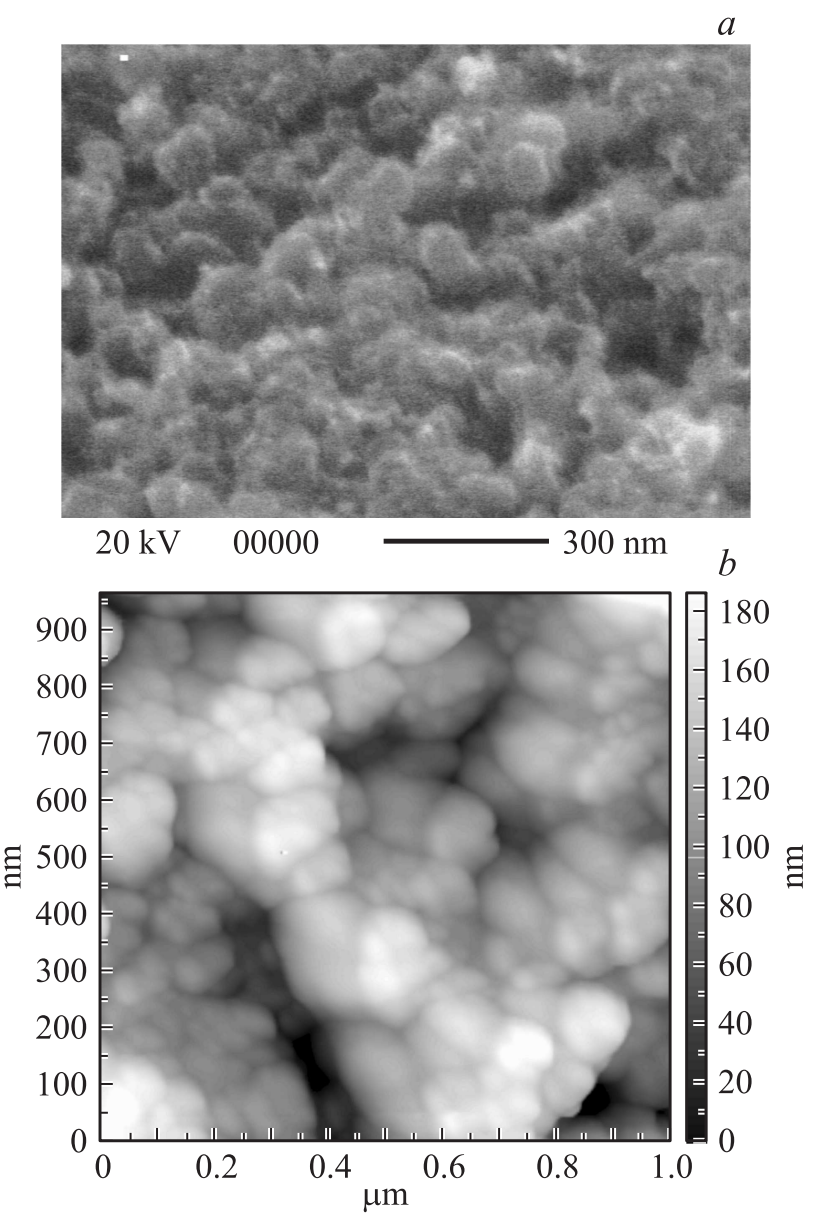

Рис. 1. Изображения поверхности электрода с Nafion без предварительного коагулирования (НАНГ-44), полученные разными методами в близких масштабах: $a-\mathrm{C} Э \mathrm{M}, b-\mathrm{ACM}$. 

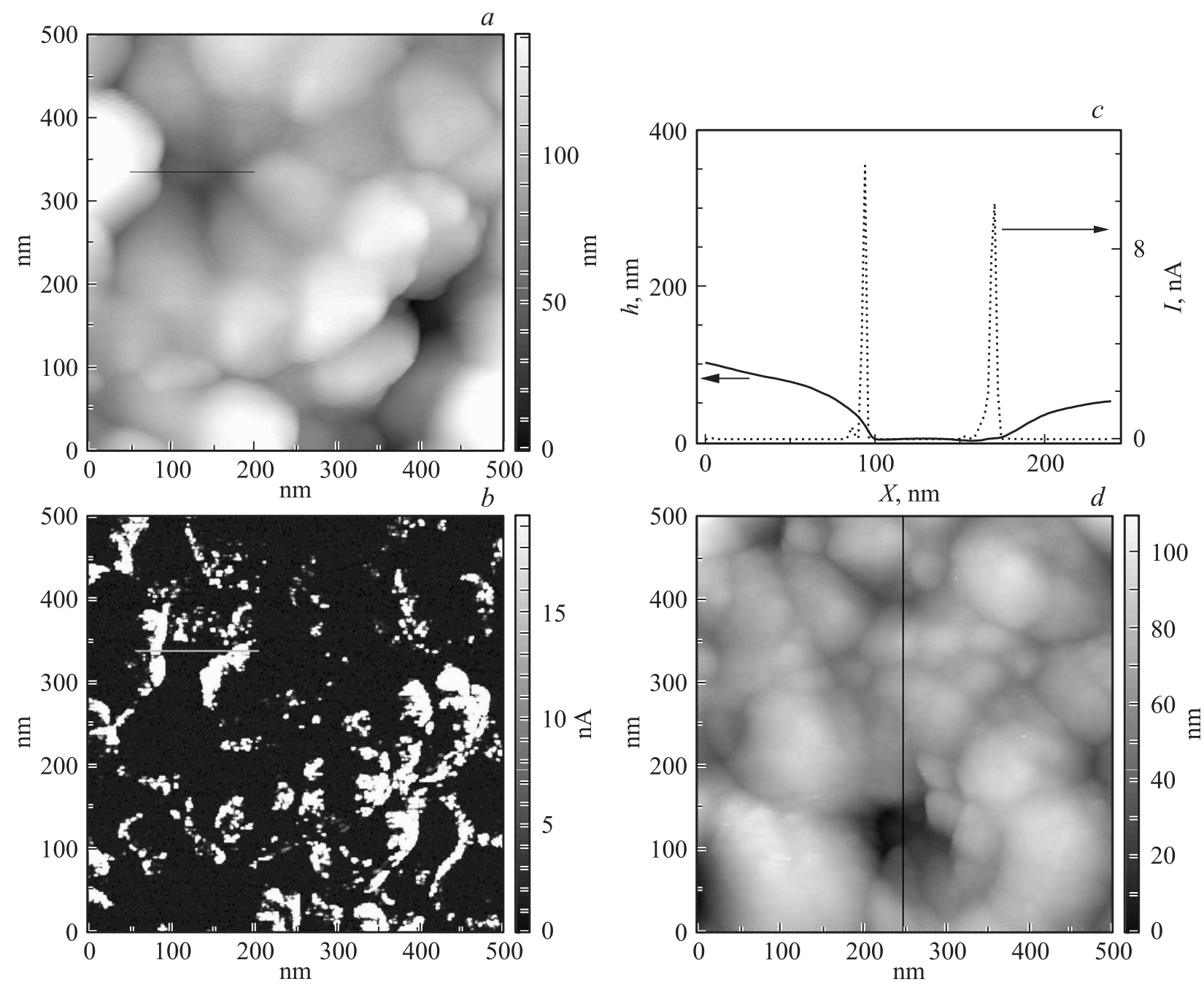

Рис. 2. Одновременно измеренные АCM топография $(a)$, карта локальной проводимости $(b)$ и совмещенные профили рельефа поверхности и тока $(c)$ для некоагулированного электрода (НАНГ-44) и для предварительно коагулированного электрода (НАНГ41) $-d, e, f$ соответственно.

считать правомерным и эффективным использование метода АСМ для исследования структуры электродов данного типа.

На рис. 2 представлены измеренные одновременно АСМ топографии, карты локальной проводимости и совмещенные профили рельефа поверхности и тока. Рис. 2, $a-c$ соответствуют случаю, когда Nafion вводился в электрод без предварительного коагулирования, а рис. $2, d-f-$ случаю, когда Nafion был предварительно коагулирован.

Максимальный перепад высот $\Delta Z=Z_{\max }-Z_{\min }$ на АСМ-топографиях для обоих электродов сопоставим, и составляет величину $\Delta Z=140 \mathrm{~nm}$ для НАНГ-44 (рис. $2 a$ ) и $\Delta Z=110 \mathrm{~nm}$ для НАНГ-41 (рис. $2, d$ ). Также сопоставимы и значения шероховатостей для НАНГ-44 $(R M S=18 \mathrm{~nm}) \quad$ и НАНГ-41 $(R M S=19 \mathrm{~nm})$. Однако существенное отличие наблюдается в токовых картах локальной проводимости на рис. $2, b$ и $2, e$. Из данных рис. $2, b$ видно, что области повышенной проводимости (белые области) преимушественно располагают- ся на границах шарообразных структурных элементов, что подтверждается совмещенными профилями рельефа (пунктирная линия на рис. 2,a) и тока (пунктирная линия на рис. $2, b)$, представленными на рис. $2, c$. В случае предварительно коагулированного Nafion (pис. 2,e) области повышенной проводимости располагаются более равномерно по поверхности электрода, что также подтверждается совмещенными профилями, представленными на рис. 2,e. Видно, что области повышенной проводимости (всплески на рис. 2,e) расположены как между шарообразными структурными элементами, так и на их поверхности. Это может указывать на отсутствие Nafion в данной области (см. рис. 3).

При сравнении карт областей проводимости электрода с некоагулированным (рис. 2, $b$ ) и с коагулированным Nafion (рис. 2,e) видно, что в первом случае непроводящая область покрывает поверхность большей площади и с меньшим количеством разрывов сплошности, чем в случае с коагулированным Nafion. Это можно объяснить образованием пленки Nafion, покрывающей 


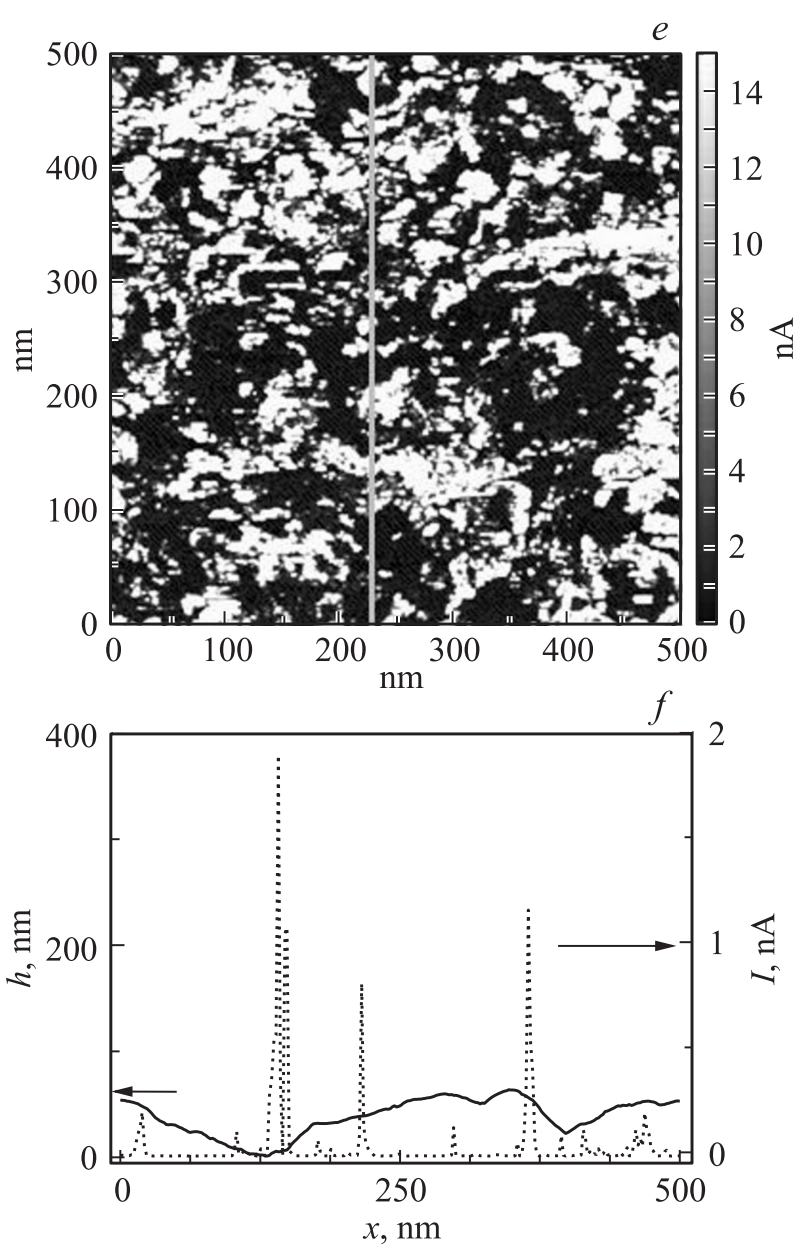

Рис. 2 (продолжсение).

Таблица 2. Состав образцов, использованных для микроскопических исследований

\begin{tabular}{l|c|c}
\hline $\begin{array}{l}\text { Образец } \\
\text { МЭБ / характеристика }\end{array}$ & НАНГ-44 & НАНГ-41 \\
\hline $\begin{array}{l}\text { Массовая доля Nafion } \\
\text { в электроде, \% }\end{array}$ & 20 & 20 \\
\hline $\begin{array}{l}\text { Массовая доля углеродной } \\
\text { сажи в электроде, \% }\end{array}$ & 48 & 48 \\
\hline $\begin{array}{l}\text { Массовая доля Pt } \\
\text { в электроде, \% }\end{array}$ & 32 & 32 \\
\hline $\begin{array}{l}\text { Содержание Pt в электроде, } \\
\text { тg/ст }\end{array}$ & 0.52 & 0.30 \\
\hline $\begin{array}{l}\text { Форма вводимого } \\
\text { в электродный } \\
\text { материал Nafion }\end{array}$ & Раствор & Скоагулированный \\
\hline
\end{tabular}

значительную часть электрода, при введении его в некоагулированной форме, что согласуется с литературными данными [4,5]. В случае же введении Nafion в предварительно скоагулированном состоянии он присутствует
Таблица 3. Значения величин удельной площади электрохимически активной поверхности платины и пористости для электродов с различной формой Nafion

\begin{tabular}{c|c|c|c|c}
\hline $\begin{array}{c}\text { Образец } \\
\text { МЭБ }\end{array}$ & Форма Nafion & $\begin{array}{c}\text { Массовая доля } \\
\text { Nafion } \\
\text { в электроде, } \%\end{array}$ & $\begin{array}{c}S_{\text {Ptsp., }} \\
\mathrm{m}^{2} / \mathrm{g}\end{array}$ & $\begin{array}{c}\text { Пористость, } \\
\%\end{array}$ \\
\hline НАНГ-53 & Не коагулирован & 20 & 28 & 67 \\
НАНГ-41 & Коагулирован & 20 & 60 & 73
\end{tabular}

в виде отдельных агломератов, что проявляется в виде множества отдельных непроводящих областей (рис. 2,e).

BAX контакта ACM-зонда с поверхностью электрода (независимо от формы, в которой присутствует Nafion) имеют линейный характер. Кроме того, отсутствует гистерезис при подаче обратного напряжения. Эти обстоятельства указывают на то, что проводящими фазами действительно являются углеродная сажа и платина, входящие в состав электродов, и отсутствуют токи заряжения двойного электрического слоя и электрохимических процессов. В противном случае, при протекании электрохимической реакции, в ВАХ наблюдался гистерезис [13].

В табл. 3 сведены данные об удельной площади электрохимически активной поверхности платины и пористости для электродов, изготовленных с использованием некоагулированного и коагулированного Nafion. Данные усреднены по двум электродам.

Как видно из данных таблицы, коагулирование Nafion перед введением его в электродный материал существенно сказывается как на удельной площади электрохимически активной платины, так и на пористости электрода. В обоих случаях коагулирование Nafion приводит к увеличению этих величин. Эти результаты согласуются

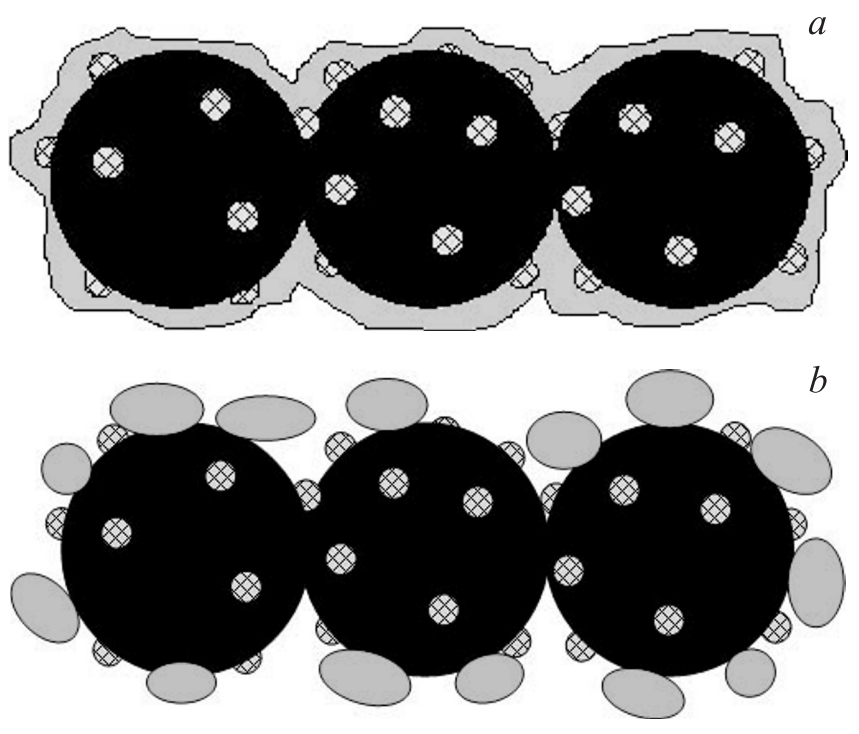

Рис. 3. Модельные представления структуры электрода с различной структурой Nafion: $a-$ пленочная структура Nafion, $b-$ „островковая“ структура Nafion. 
с различными структурами, образуемыми Nafion в электроде в зависимости от его формы - пленочной без коагулирования и „островковой“ в случае коагулирования, как показано выше.

\section{Выводы}

1. Впервые использован прием введения Nafion в электродный материал в коагулированном состоянии, позволивший существенно увеличить удельную площадь поверхности платины и пористость электрода.

2. Показана эффективность использования метода полуконтактной микроскопии сопротивления растекания для исследования структуры композитных электродов со смешанной проводимостью, содержащих полимерный материал Nafion.

3. При введении Nafion в электродный материал в виде раствора он образует пленочную структуру и блокирует значительную часть поверхности платины, в случае предварительно коагулированного Nafion он образует „островковую“ структуру и за счет этого блокированная доля поверхности платины меньше.

4. Использование коагулированного Nafion позволит оптимизировать электроды топливных элементов и повысить эффективность источников токов в целом.

\section{Список литературы}

[1] Hao L., Moriyama K., Gu W., Wang C.-Y. // J. Electrochem. Society. 2015. Vol. 162, N 8. P. F854-F867.

[2] Passalacqua E., Lufrano F., Squadrito G., Patti A., Giorgi L. // Electrochimica Acta. 2001. Vol. 46. P. 799-805.

[3] Antolini E., Giorgi L., Pozio A., Passalacqua E. // J. Power Sources. 1999. Vol. 77. P. 136-142.

[4] Zhang J. // PEM Fuel Cell Electrocatalysts and Catalyst Layers. Vancouver: Springer, 2008. 1137 p.

[5] Litster S., McLean G. // J. Power Sources. 2004. Vol. 130. P. 61-76.

[6] Нечитайлов А.А., Глебова Н.В., Кочкина Д.В., Томасов А.А., Зеленина Н.К., Терукова Е.Е. // Письма в ЖТФ. 2013. Т. 39. Вып. 17. С. 15-26.

[7] Кашин А.С., Анаников В.П. Изв. АН Сер. Хим. 2011. № 12. C. 2551-2556.

[8] Анкудинов А.В., Гущина Е.В., Гуревич С.А., Кожевин В.М., Горохов М.В., Коньков О.И., Терукова Е.Е., Титков А.Н. // Альтернативная энергетика и экология. 2008. № 10 (66). С. 30-36.

[9] Электронный ресурс. Режим доступа: http://www.ntmdt.ru/modular-afm

[10] Электронный ресурс. Режим доступа: http://www.ntmdttips.com

[11] Нечитайлов А.А., Глебова Н.В. // Электрохимия. 2014. T. 50. C. 835-840.

[12] Пат. РФ № 2487442. Способ активации мембранноэлектродного блока. / Д.А. Андроников, Н.К. Зеленина, Е.Е. Терукова, А.А. Томасов. 2012.

[13] Анкудинов А.В., Глебова Н.В., Гущина Е.В., Нечитайлов А.А., Терукова Е.Е., Боброва Л.П., Тимофеев С.В. // Альтернативная энергетика и экология. 2008. № 10 (66). C. 79-82. 